\title{
Analyzing the Role of Organizational Culture in the Implementation of User-Centered Design:
}

Disentangling the Approaches for Cultural Analysis

\author{
Netta livari \\ University of Oulu, Department of Information Processing Science, Finland
}

\begin{abstract}
Usability is an important quality characteristic of a software product or system. User-centered design (UCD) is an approach focusing on making systems usable. Improving the position of UCD in organizations has proven to be a challenge. Organizational culture has been identified as an influential factor affecting the successes and failures of organizational improvement efforts. However, there does not exist studies of the effects and consequences of organizational culture in the implementation of UCD. In addition, there exists a lack of methods and theoretical models with which to reliably, systematically and meaningfully analyze organizational culture in relation to improvement efforts. This paper examines existing research within organizational studies, and proposes three approaches - comparative, interpretive and clinical - within which the role of organizational culture can be examined in relation to implementation of UCD. Implications for prospective research are outlined.
\end{abstract}

Key words: organizational culture, user-centered design, approaches for cultural analysis

\section{INTRODUCTION}

This paper examines existing research on organizational culture, and proposes approaches through which it could be utilized in relation to research on implementing "User-Centered Design" (UCD) or "HumanCentered Design" defined in (ISO 13407, 1999) and interpreted by Jokela (2001) into organizations. UCD as a systems design approach is characterized by its goal of producing usable systems and principles of user participation, an appropriate allocation of functions between users and technology, iterative design and multi-disciplinary design. UCD activities include: 1) understanding and specifying the context of use; 2) specifying the 
user and organizational requirements; 3) producing design solutions; and 4) evaluating designs against requirements. (ISO 13407, 1999). However, it might be more appropriate to speak about usability-centered design than user-centered design since many earlier systems design approaches, which do not share all the above goals and principles, are user-centered (e.g. the socio-technical design approach). UCD is defined method independently in the standard. Design approaches focusing on users and usability, e.g. contextual design (Beyer \& Holtzblatt, 1998) and usability engineering (Mayhew, 1999), are interpreted as offering specific methods and techniques for UCD activities.

This research effort is part of a KESSU-research project, which aims to introduce and implement UCD in software development organizations, in which the position of UCD is often nonexistent or ineffective (Jokela, 2001). In addition, the improvement of the position of UCD has been widely recognized as a challenge (Axtell \& Waterson, 1997; Jokela, 2001; Rosenbaum, 1999). There exists a need for more thorough understanding of the process of implementing UCD into organizations. We suggest that organizational culture is a factor that is intimately intertwined with the organizational change effort of introducing UCD into organizations.

Organizational culture has lately been a popular focus of analysis in studies on organizational change and development (Denison \& Spreitzer, 1991). Studies have also examined the part culture plays in achieving total quality through total quality management (TQM). Culture is seen as a major cause of failure in the implementation of TQM (Detert et al, 2000: Kekäle, 1998). However, there still exist severe problems in understanding why so many change programs fail or do not diffuse into the organizations (Schein, 1996). In addition, there exists a need for methods and theoretical models with which to reliably, systematically and meaningfully analyze organizational culture in relation to improvement efforts (Denison \& Spreitzer, 1991; Hatch, 1997; Smircich, 1983).

This research effort began with a literature search on several electronic on-line databases. Not a single study was found addressing the role of organizational culture in relation to implementing UCD into organizations. This paper takes a step toward that direction. First the concept of culture is specified. In cultural anthropology, culture denotes the socially transmitted patterns for behavior characteristic of a particular social group (Keesing \& Strathern, 1998; Kroeber \& Kluckhohn, 1952). It refers to a way of life among particular people. Culture is historical, learned, taken for granted, shared, and ideational. (Keesing \& Strathern, 1998; Kroeber \& Kluckhohn, 1952.) Culture is a symbolic system. A socio-cultural system is made up of routinized, adaptive, patterned forms of interaction. A symbolic system, on the other hand, consists of learned, shared, patterned sets of meanings. The 
distinction is between patterns of behavior and patterns for behavior - culture refers to the realm of ideas. (Keesing \& Strathern, 1998; Lett, 1987.) Organizational culture, consequently, refers to the shared patterned sets of meanings for behavior in organizations.

The paper is organized as follows. The next section outlines the existing approaches in organizational culture studies, and highlights the epistemological, methodological and ethical differences in the approaches. Afterwards, three different approaches for cultural studies - comparative, interpretive and clinical - are presented in more detail, and their implications for studies on the implementation of UCD are outlined. The final section discloses the central themes and observations of the paper.

\section{APPROACHES IN ORGANIZATIONAL CULTURE STUDIES}

Organizational culture is a versatile concept (Smircich, 1983). In order to understand and meaningfully study organisational culture, it is paramount to comprehend its relationship with the evolution of thought in organization theory. Hatch (1997) identifies four perspectives in the development of organization theory. The first one is the classical period, which began in the beginning of last century. The modern perspective emerged in the 1950s. The symbolic interpretive perspective gained attention in the 1980s. The postmodern perspective emerged in the 1990s. Especially the modern and the symbolic interpretive perspective are widely used in organizational culture studies. (Hatch, 1997; Schultz, 1994.)

During the modern period the researchers focused on organizations through objective measures. The methods used were statistical. Results achieved were comparative studies and multivariate statistical analyses. Relying on notions of the positivist research tradition, scientific methods were preferred and scientific objectivity was emphasized. Surveys were commonly used for data gathering. (Burrell \& Morgan, 1979; Hatch, 1997.) The symbolic interpretive perspective, on the other hand, aimed at counterbalancing the functionalist-positivist (Burrell \& Morgan, 1979; Hatch, 1997) paradigm. This perspective relies on thoughts developed within cultural anthropology. The organizations were now approached through subjective perceptions and the analysis was contextualized; the phenomena were studied in situations in which they naturally occurred, from the 'natives point of view'. (Burrell \& Morgan, 1979; Hatch, 1997.)

Schultz and Hatch (1996) outline two paradigms - functionalism and interpretivism - in organizational culture studies. Culture studies following the functionalist paradigm are based on an analytical framework that is 
defined prior to entering an organization. The framework used is generalized for all organizations studied. The analysis is conducted by filling in predefined variables and mapping causal relations between them. The aim is to condense and bring elements of cultural analysis together. Interpretivism, relying on the symbolic interpretive tradition on the other hand, offers the greatest contrast to functionalism's assumptions. It approaches culture from the 'native's point of view'. The constructs for describing the culture are suggested by the analysis. Focus is on the active creation of meanings and on the ways in which meanings are associated in organizations. Analysis is context-sensitive and concentrates on local, specific meanings.

Table 1. outlines three approaches in organizational culture studies comparative, interpretive and clinical - and summarizes their underlying epistemological, methodological and ethical assumptions.

\begin{tabular}{|c|c|c|c|}
\hline Approach & Epistemology & Methodology & Ethics \\
\hline $\begin{array}{l}\text { 1. Comparative: } \\
\text { Survey instruments: } \\
\text { culture is approached } \\
\text { as comparative traits } \\
\text { and dimensions, } \\
\text { measured as values or } \\
\text { attitudes } \\
\text { Influenced by modern } \\
\text { perspective, } \\
\text { quantitative } \\
\text { organizational climate } \\
\text { studies (Denison, } \\
\text { 1996; Hatch, 1997; } \\
\text { Schultz \& Hatch, } \\
\text { 1996) }\end{array}$ & $\begin{array}{l}\text { Positivism: seeks to } \\
\text { explain and predict } \\
\text { what happens in } \\
\text { social world by } \\
\text { searching for } \\
\text { regulaties and causal } \\
\text { relationships between } \\
\text { constituent elements. } \\
\text { (Burrell \& Morgan, } \\
\text { 1979) } \\
\text { Scientific knowledge } \\
\text { consists of regulaties, } \\
\text { causal laws and } \\
\text { explanations (Burrell } \\
\text { \& Morgan, 1979) }\end{array}$ & $\begin{array}{l}\text { Nomothetic } \\
\text { methods } \\
\text { (Burrell \& } \\
\text { Morgan, } \\
\text { 1979): } \\
\text { - Experiments } \\
\text { - Field studies } \\
\text { and surveys } \\
\text { Formal } \\
\text { mathematical } \\
\text { analysis }\end{array}$ & $\begin{array}{l}\text { Means-end } \\
\text { oriented: culture is } \\
\text { studied in order to } \\
\text { derive cause and } \\
\text { effect relationships } \\
\text { (Chua, 1986) } \\
\text { Serves the interests } \\
\text { of the research }\end{array}$ \\
\hline $\begin{array}{l}\text { 2. Interpretive: } \\
\text { Ethnographic case } \\
\text { studies: culture is } \\
\text { approached as a } \\
\text { pattern of meanings. } \\
\text { Influenced by the } \\
\text { symbolic interpretive } \\
\text { perspective, tradition } \\
\text { of cultural } \\
\text { anthropology } \\
\text { (Czarniawska-Joerges, } \\
\text { 1992; Hatch, 1997; } \\
\text { Schultz \& Hatch, } \\
\text { 1996; Smircich, 1983) }\end{array}$ & $\begin{array}{l}\text { Antipositivism: social } \\
\text { world can only be } \\
\text { understood from the } \\
\text { point of view of } \\
\text { individuals who are } \\
\text { directly involved in } \\
\text { the activities which } \\
\text { are to be studied. } \\
\text { (Burrell \& Morgan, } \\
\text { 1979) } \\
\text { Scientific knowledge } \\
\text { consists of human } \\
\text { interpretations and } \\
\text { understandings } \\
\text { (Burrell \& Morgan, } \\
\text { 1979) }\end{array}$ & $\begin{array}{l}\text { Idiographic } \\
\text { methods } \\
\text { (Burrell \& } \\
\text { Morgan, } \\
\text { 1979): } \\
\text { - Case studies } \\
\text { Context and } \\
\text { organization } \\
\text { specific, } \\
\text { interpretive } \\
\text { analysis }\end{array}$ & $\begin{array}{l}\text { Interpretive: culture } \\
\text { is studied in order } \\
\text { to enrich people's } \\
\text { understanding of } \\
\text { their action (Chua, } \\
\text { 1986) } \\
\text { Serves the interests } \\
\text { of the research } \\
\text { Sympathetic to the } \\
\text { cultural community } \\
\text { studied }\end{array}$ \\
\hline
\end{tabular}




\begin{tabular}{|c|c|c|c|}
\hline 3. Clinical: & Epistemology: & Methodology: & Ethics: \\
\hline $\begin{array}{l}\text { Consultant oriented } \\
\text { investigations: culture } \\
\text { is approached as a tool } \\
\text { for problem solving } \\
\text { Influenced by systems } \\
\text { approach \& } \\
\text { contingency view, } \\
\text { organizational } \\
\text { psychology, tradition } \\
\text { of organizational } \\
\text { development } \\
\text { (Czarniawska-Joerges, } \\
\text { 1992; Denison \& } \\
\text { Spreitzer, 1991; } \\
\text { Schein, 1985; } \\
\text { Smircich, 1983) }\end{array}$ & $\begin{array}{l}\text { Either positivist or } \\
\text { antipositivist }\end{array}$ & $\begin{array}{l}\text { Either } \\
\text { nomothetic or } \\
\text { idiographic } \\
\text { Universal } \\
\text { analytical } \\
\text { framework } \\
\text { Clinical } \\
\text { analysis }\end{array}$ & $\begin{array}{l}\text { Means-end oriented } \\
\text { (Chua, 1986); } \\
\text { culture is studied in } \\
\text { order to solve } \\
\text { organizational } \\
\text { problems } \\
\text { Ideology of } \\
\text { managerialism } \\
\text { (Burrell \& Morgan, } \\
\text { 1979; Czarniawska- } \\
\text { Joerges, 1992)- } \\
\text { organization and } \\
\text { management } \\
\text { oriented, serves the } \\
\text { needs of the client }\end{array}$ \\
\hline
\end{tabular}

Table 1, Three approaches in organizational culture studies

The approaches are identified following the division of paradigms in organization theory presented in (Burrell \& Morgan, 1979; Hatch, 1997; Schultz \& Hatch, 1996). The comparative approach reflects the modern perspective, following the functionalistic paradigm (Burrell \& Morgan, 1979; Schultz \& Hatch, 1996). The functionalist paradigm implies positivist epistemology and nomothetic research methodology. The interpretive approach follows the interpretive paradigm (Burrell \& Morgan, 1979; Schultz \& Hatch, 1996). The interpretive paradigm implies antipositivist epistemology and idiographic research methodology. The clinical, consultoriented approach (Schein 1985; Deal \& Kennedy, 1982; Peters \& Waterman, 1982), also discussed by Czarniawska-Joerges (1992), is included in the functionalistic paradigm in (Schultz \& Hatch, 1996). We interpret, however, that it has followed both the functionalist and interpretive paradigm. Even if it is often applied in a functionalist spirit when measuring organizational cultures; it has also been intermingled with the interpretive approach (methodologically in Schein, 1985). Therefore we suggest that the comparative and the clinical approach should be distinguished.

The ethics of research allows highlighting further differences between the three approaches. In his analysis of paradigmatic assumptions of information systems development approaches, livari (1991) interprets the ethics as the role and values of research. In relation to the role of the research, both the clinical and comparative approaches are means-end oriented approaches, in which "scientists aim at providing means knowledge for achieving certain ends without questioning the legitimacy of the ends" (Iivari, 1991), while the 
interpretive approach aims at "enriching people's understanding of their action and of how social order is produced and reproduced" (Iivari, 1991). Also the values of the research, whose interests the research serves (Iivari, 1991), differ between the approaches. The comparative and interpretive approaches aim at serving those of the academia, but in the clinical approach the needs of the client are the main motivators for the research, the clients often being the management of the organization studied. In an extreme, the managers are conceived as creators and manipulators of the organizational culture and the cultural analysis only assists the managers in the pursuit for excellence. (Czarniawska-Joerges, 1992; Schein, 1985). This clearly conflicts with the anthropological notion of understanding, not interfering with, applied in studies within an interpretive paradigm. Within the interpretive approach the researchers consider carefully the implications of the research for the lives of the researched. Self-reflection of the researchers and ethics of research are in a central position.

Next the approaches are presented in more detail and their implications for research on the role of organizational culture in the implementation of UCD are outlined.

\section{THE COMPARATIVE APPROACH}

\subsection{Introduction to the comparative approach}

Within the comparative approach, culture is studied as comparative traits or dimensions. Culture is measured as values, norms or attitudes. The measurement relies on certain typology based on general characteristics of organizational culture. The aim is not to highlight the unique qualities of cultures, but rather to group and profile them. The comparative approach relies on survey instruments to categorize and measure cultures. The instruments position cultures on a certain scale or typology. (Denison, 1996; Denison \& Spreitzer, 1991; Kekäle, 1998.)

Competing values model has been popular in diagnosing organizational cultures from the comparative cultural perspective (e.g. Denison \& Spreitzer, 1991; Quinn \& Spreitzer, 1991; Tata \& Prasad, 1998; Zammuto \& Krakower, 1991; Iivari \& Huisman, 2001). The model consists of two axes that reflect different value orientations. The vertical axis is flexibility control dimension. Flexibility-oriented cultures support decentralization and differentiation, control-oriented support centralization and integration. The horizontal axis is internal - external dimension. Internal-focused cultures support maintenance of the existing system, while externally focused seek 
improvements and track changes in their environment. By positioning organizations within the axes they can be defined within four organizational culture types: group, developmental, rational and hierarchical culture. (Denison \& Spreitzer, 1991.)

From the viewpoint of implementing UCD the competing values model has been applied in two relevant fields: to study the implementation of TQM and to analyze the deployment of systems development methodologies (SDMs). The former studies suggest that the developmental type of culture is most strongly linked to a TQM success (Dellana \& Hauser, 1999; Tata \& Prasad, 1998). This implies that the congruent organizational culture for $\mathrm{TQM}$ is that of a flexibility-oriented, emphasizing decentralization, differentiation and external orientation. (Dellana \& Hauser, 1999; Tata \& Prasad, 1998.) On the other hand, research on the relationship between organizational culture and the deployment of SDMs, Iivari and Huisman (2001) show that the SDM deployment, as perceived by systems developers, was primarily associated with the hierarchical culture type. The hierarchical culture is oriented towards security, order and routinization (Denison \& Spreitzer, 1991). At the same time, the deployment, as perceived by the management, was negatively associated with the rational culture (livari \& Huisman, 2001). The rational culture is focused on productivity, efficiency and goal achievement (Denison \& Spreitzer, 1991).

Accordingly, the studies indicate that different types of organizational culture are more responsive to TQM, and to the SDMs on the other hand. Iivari and Huisman (2001) study the relationship between organizational culture and SDMs without making a distinction between different methodologies. They use the term "methodology" in a very broad sense to cover the totality of SD approaches, process models, specific methods and specific techniques. In order to evaluate whether their results concerning SDMs are valid in the case of UCD, one should explore the relationship between UCD and SDMs in more detail. Similarly, the connection between UCD and TQM need to be explored before deriving hypotheses of the suitable culture type for the UCD and its implementation.

Also another kind of instruments exists for the cultural studies. Kekäle (1998) has measured organizational culture in relation to TQM implementation. He assumes that the implementation of TQM should rely on different TQM tools in different culture types. He has used a categorization of TQM tools into hard, soft and mixed. Hard TQM tools emphasize written work procedures and accurate measurement of performance. Soft tools promote innovative solutions, teamwork and employee empowerment. Kekäle suggests that there is no one-size-fits-all approach in the implementation of TQM. The approach should be tailored - compatible tools 
selected for the implementation - so that the approach fits the target culture. Cultural change should be kept the smallest possible.

This is an interesting point of view that relates also to the implementation of UCD. It could be assumed that different tools and methods in relation to UCD are accepted differently. Probably there is no one-size-fits-all approach in relation to UCD either. This viewpoint is in accordance also with the theory of diffusion of innovations, in which it is suggested that the compatibility of the innovation with the existing practice, values and norms contribute positively to the rate of adoption.

\subsection{Implications of the comparative approach}

A considerable strength of the comparative approach is that the instruments developed to measure organizational culture can be used for collecting comparable data from organizations implementing UCD. Data gathering may be initiated relatively easily with these types of instruments. The instruments can also be used for follow up analyses. In addition, through use of the instruments the validity of the findings derived within other approaches can be enhanced.

The comparative approach to organizational culture has both theoretical and practical implications from the viewpoint of UCD. From a theoretical viewpoint it leads to the following research questions:

- Does the success of UCD differ in organizations with different cultures?

- Does organizational culture explain differences in the success of UCD?

- Do some types of organizational cultures facilitate or constrain the implementation (adoption) of UCD?

- What is the nature of the concept of "cultural fit" of UCD and its implementation?

The studies of the relationship between organizational culture and TQM implementation (Dellana \& Hauser, 1999; Kekäle, 1998; Tata \& Prasad, 1998) and between organizational culture and SDM deployment (Iivari \& Huisman, 2001) suggests that the success UCD and its implementation may differ in organizations with different cultures. Research reviewed above also leads us to the question of whether "cultural fit or misfit" is a singular concept in the sense that there is an ideal organizational culture for UCD and its implementation and that UCD is totally incompatible with some types of organizational cultures. The proposals (Dellana \& Hauser, 1999; Tata \& Prasad, 1998) that the developmental type of culture is most strongly linked to TQM reflect this view. Alternatively, the findings in (Kekäle, 1998), when applied to UCD, would suggest that "cultural fit or misfit" could be a plural concept in the sense that it is specific to different UCD tools and methods.

From a more practical viewpoint one may raise a number of questions: 
- What kind of values and norms constitute an 'ideal UCD culture'?

- What are the compatible culture types for UCD implementation?

- How can UCD be aligned with the type of the organizational culture?

- Should one introduce different UCD tools and methods for different types of organizations?

The first question rephrases the idea of cultural fit in more concrete terms. For the analysis of ideal assumptions, values and norms supporting UCD culture, similar kinds of research in the field ideal TQM culture is available (Detert et al, 2000; Kekäle, 1998). The second question points to a distinction between cultural fit of UCD and its implementation. Assuming UCD is sensitive to the organizational culture and that the client organization has a certain culture that is neither totally ideal nor totally incompatible with UCD, the question is how to align UCD with the organizational culture? Does UCD have cultural flexibility so that it can be adapted to different types of organizational cultures?

\section{THE INTERPRETIVE APPROACH}

\subsection{Introduction the interpretive approach}

An interpretive approach is the traditional approach within cultural studies. It relies on the use of ethnography as the main method for data gathering. Ethnography is derived from the tradition of cultural anthropology. Cultural anthropology studies local small-scale communities on a basis of intimate participation in the daily lives of the members of the community. Distinctive features are holism, comparison, participative observation, appreciation of both cultural differences and human commonalities, and emphasis on cultural context. Anthropology highlights the importance of interpretations of collective action, understandings from the 'native's point of view' and constant search for new meanings and interpretations through problematizing the familiar. Researchers' assumptions and predefined categories do not restrict the data gathering to certain traits or dimensions that are of interest to the researcher, but not necessarily to the cultural members studied. Qualitative data is to be gathered and subsequently mapped, but only after data gathering. (Czarniawska-Joerges, 1992; Keesing \& Strathern, 1998.)

The researchers spend long periods of time in organizations, participating in the daily activities with the cultural members, and trying to understand the culture from the native's point of view. The data collection concentrates on qualitative data. Material from in-depth interviews, participant observation and field notes written by the researchers are typical. During the fieldwork 
period the aim is not to disturb the everyday life in the organization. The research effort may however lead to reflection done by cultural members. Due to this self-reflection of the researchers, the ethics of the research are in a central position. (Czarniawska-Joerges, 1992; Schultz, 1994.)

\subsection{Implications of the interpretive approach}

The interpretive approach is useful since it provides grounded, specific, context sensitive data and understandings from the native's point of view. It addresses issues important to the cultural members, not those predefined as important by the researchers. It has both theoretical and practical implications from the viewpoint of UCD and its implementation. For example, the following theoretical research questions are of interest:

- How is UCD encultured in organizations?

- What meanings are attached to UCD in practice?

- Is there "symbolic uses of UCD"?

One can claim that in order to become an effective part of the everyday systems design practice; UCD should become part of the organization's design culture. This leads to the question of how UCD is encultured in practice. We have examined (Iivari \& Abrahamsson, 2002) the interpretations and understandings of UCD and its implementation in relation to different organizational subcultures interacting in the implementation of UCD in one software development company participating in the KESSU project. The subcultures identified were: 1) the usability specialists actively involved in the improvement; 2) the software engineers representing the viewpoint of the software development, who are a significant target of the improvement effort; and 3) the (senior) managers who sponsor the improvement.

The focus of our study was on the perceptions of the nature of UCD, the motives for implementing it, and the experiences while using it in relation to each subculture. The results reveal that there exist clear differences in the perceptions in relation to each subculture. Software engineers and managers especially had attached quite surprising meanings to UCD and its implementation (Iivari \& Abrahamsson, 2002):

- The software engineers viewed UCD to be difficult to understand, too theoretical in nature, and containing too complicated terminology. They had a skeptical attitude towards the improvement effort and suspicions about the usefulness of UCD methods.

- The (senior) managers also deemed UCD to be too theoretical in nature and to contain complicated terminology. However, the managers had a very enthusiastic attitude towards the improvement. They conceived $\mathrm{UCD}$ as a tool for taming the customers, for keeping customers out of the 
development, and for improving the image of the company. They also viewed the implementation effort as a tool for spreading knowledge and skills organization wide.

The results reveal that the subcultures have incongruent views, attitudes, expectations and assumptions concerning UCD and its implementation. Software engineers' very skeptical attitude and the managers' 'symbolic uses of UCD' are factors likely to influence the implementation of UCD (Iivari \& Abrahamsson, 2002). However, the interpretations and understandings of UCD, the symbolic uses of UCD, and the process of enculturation of UCD into organizations need all to be empirically explored further.

\section{THE CLINICAL APPROACH}

\subsection{Introduction to the clinical approach}

The clinical approach has sometimes been dismissed as an unscientific endeavor, but it has been applied also in research efforts of a scientific nature. (Czarniawska-Joerges, 1992). Within the clinical approach, culture is conceived as a tool for problem solving. Schein defines organizational culture to be "a pattern of basic assumptions - invented, discovered, or developed by a given group as it learns to cope with its problems of external adaptation and integral integration - that has worked well enough to be considered valid and, therefore, to be taught to new members as the correct way to perceive, think, and feel in relation to those problems" (Schein, 1985). Schein presents a detailed description of different steps of his approach, within which the mode is clinical, therapeutic. (Schein, 1985).

In the clinical approach there exists a psychological contract between the client and the consultant. The organization needs to be motivated for the joint discovery. Due to this there needs to be a problem before the intervention. The aim of the approach is to address organizational problems and dysfunctions, and how they contribute to the survival of organization. (Schein, 1985; Schultz, 1994.) The research effort is guided by the needs of the client. The clients are usually the managers of the organization. Within this approach an extreme is that managers are seen as creators and manipulators of organizational culture, and the research effort only assists in the pursuit for excellence. (Deal \& Kennedy, 1982; Peters \& Waterman, 1982). This type of clinical approach, however, has been criticized as being an unscientific endeavor (Czarniawska-Joerges, 1992).

Czarniawska-Joerges (1992) warns that within the clinical approach the studies on organizational culture are often connected to cultural anthropology, but in many cases the reference to anthropology is used just as 
a label, not as an approach. Consultant-oriented researchers have used anthropological concepts, but only as attractive metaphors. This has nothing to do with analytic purposes, but instead with the purposes of control. However, the clinical approach, when relying on the approach defined by Schein (1985), conceives organizational culture in more depth than just as an attractive metaphor, and applies many anthropological viewpoints.

\subsection{Implications of the clinical approach}

The clinical approach provides guidance on how to help an organization. In all, the clinical approach does not result in very interesting theoretical research questions. Its main contribution is the consultant-oriented, clientfocused research mode, which might offer visible, practical benefits for target organizations during the implementation effort. Furthermore, the approach in (Schein, 1985) is useful since with it:

- The basic assumptions can be analyzed with detailed guidelines

- The organizational problems and dysfunctions can be addressed

- The effects of the basic assumptions on the implementation of UCD, and the effects of the implementation of UCD on the problems of external adaptation or internal integration can be considered

\section{CONCLUDING REMARKS}

Organizational culture has been recognized as an important topic of study since the early 1980's. It has been acknowledged as an influential factor affecting the successes and failures of organizational improvement programs. However, there do not exist organizational culture studies in relation to the implementation of UCD. Undoubtedly studies of this kind are needed, since the implementation of UCD has proven to be challenging. However, culture is a versatile concept, and thus there exists controversies in both defining and applying it. Therefore this paper has analyzed the existing paradigms in organizational culture studies and outlined three approaches comparative, interpretive and clinical - for the purposes of the culture studies. Finally, the implications of the three research approaches for the research on the implementation of UCD have been presented.

All the approaches should be acknowledged as useful in the pursuit of understanding the role of organizational culture in the implementation of UCD. This kind of multi-paradigmatic research into organizational culture benefits from triangulation and the use of a variety of methods. Through this the researchers can develop grounded, but general theories. Therefore, the approaches should be seen as complementary, not incompatible ones. 
(Czarniawska-Joerges, 1992; Denison, 1996; Denison \& Spreitzer, 1991; Schultz \& Hatch, 1996; Zammuto \& Krakower, 1991.)

The comparative approach contributes to the research effort by offering:

- Comparable data from different organizations - generalizations

- First hand information about the value orientation of the organization possible guidelines for selection of an implementation strategy

- Easy and quick follow up analyses

- Triangulation: enhancement of the validity of the findings derived within interpretive or clinical approach, and

- Predefined frameworks for the analysis. The interpretive approach provides:

- Thorough understandings from the native's point of view.

- A research approach concentrating on the issues important to the cultural members - grounded, specific, context sensitive data - provides

- A sound research approach for qualitative research. Finally, the clinical approach is useful since:

- It focuses on the needs of the client and primarily assists the organization

- A therapeutic, client-centered mode may motivate an organization to undergo this self reflection process needed in cultural analysis.

Consequently, all the approaches - comparative, interpretive and clinical - study the same phenomena, but within different methodological, epistemological and ethical premises. It is our contention that a researcher should, while attempting to apply the approaches, be aware of their assumptions and underlying philosophies. The purpose of this paper has been to provide a condensed introduction to different approaches in organizational culture studies, and to their underlying assumptions. All the approaches suggested for trial should be viewed useful in the pursuit of understanding cultural context in the implementation of UCD. We will empirically experiment with the approaches presented in this paper within the KESSU project during future empirical research on the subject.

\section{ACKNOWLEDGEMENTS}

We would like to thank Prof. Juhani Iivari for his contribution to the paper. This research effort has been supported by INFWEST.IT Postgraduate Training Program. 


\section{REFERENCES}

Axtell, C. M., Waterson, P. E. \& Clegg, C. W. (1997): Problems integrating user participation into software development. International Journal of Human-Computer Studies 47.

Beyer, H. \& Holtzblatt, K. (1998): Contextual Design: Defining Customer-Centered Systems. San Francisco: Morgan Kaufmann Publishers, Inc.

Burrell, G. \& Morgan, G. (1979): Sociological Paradigms and Organizational Analysis. Elements of the Sociology of Corporate Life. London: Heinemann Educational Books Ltd.

Chua, W.F. (1986): Radical developments in accounting thought. Accounting Review. LXI(5).

Czarniawska-Joerges, B. (1992): Exploring Complex Organizations. A Cultural Perspective. Newbury Park: Sage Publications.

Deal, T. E. \& Kennedy, A. A. (1982): Corporate Cultures: The rites and rituals of corporate life. Reading MA: Addison-Wesley.

Dellana, S.A. \& Hauser, R.D. (1999): Toward Defining the Quality Culture. Engineering Management Journal. 11(2).

Denison, D.R. (1996): What is the difference between organizational culture and organizational climate? A native's point of view on a decade of paradigm wars. Academy of Management Review. 21(3).

Denison, D.R. \& Spreitzer, G.M. (1991): Organizational Culture and Organizational Development: A Competitive Values Approach. In Richard W. Woodman and William A. Pasmore (ed.). Research in Organizational Change and Development. An Annual Series Featuring Advances in Theory, Methodology, and Research. 5. Greenwich: JAI Press Inc.

Detert, J.R., Schroeder, R.G. \& Mauriel, J.J. (2000): A Framework for Linking Culture and Improvement Initiatives in Organizations. Academy of Management Review 25(4).

Hatch, M.J. (1997): Organization Theory. Modern, Symbolic, and Postmodern Perspectives. New York: Oxford University Press.

Iivari, J. (1991): A Paradigmatic analysis of contemporary schools of IS development. European Journal of Information Systems. Vol. 1. No. 4.

Iivari, J. \& Huisman, M. (2001): The Relationship Between Organizational Culture and the Systems Development Methodologies. Advanced Information Systems Engineering, 13th International Conference CAiSE 2001 Proceedings. Berlin: Springer-Verlag.

Iivari, N. \& Abrahamsson, P. (2002): The Interaction Between Organizational Subcultures and User-Centered Design - A Case Study of an Implementation Effort. Proceedings of the 35th Annual Hawaii International Conference on System Sciences.

ISO 13407 (1999): Human-centered design processes for interactive systems. International Standard.

Jokela, T. (2001): Assessment of user-centred design processes as a basis for improvement action. An experimental study in industrial settings. Oulu: Acta Universitatis Ouluensis Scientiae Rerum Naturalium. A 374.

Keesing, R.M. \& Strathern, A.J. (1998): Cultural Anthropology. A Contemporary Perspective. Third edition. Fort Worth: Harcourt Brave College Publishers. 
Kekäle, T. (1998): The Effects of Organizational Culture on Successes and Failures in Implementation of Some Total Quality Management Approaches. Towards a Theory of Selecting a Culturally Matching Quality Approach. Vaasa: Acta Wasaensia No 65.

Kroeber, A. L. \& Kluckhohn, C. (1952): Culture: a critical review of the concepts and definitions. Cambridge: Harvard University Press.

Lett, J. (1987): The Human Enterprise. A Critical Introduction to Anthropological Theory. Boulder: Westview Press Inc.

Mayhew, D.J. (1999): The usability engineering lifecycle: a practitioner's handbook for user interface design. San Francisco: Morgan Kaufmann Publishers, Inc.

Peters, T. J. \& Waterman, R.H. (1982): In search of excellence: lessons from America's bestrun companies. New York : Harper \& Row.

Quinn, R.E. \& Spreitzer, G.M. (1991): The Psychometrics of the Competing Values Culture Instrument and an Analysis of the Impact of Organizational Culture on Quality of Life. In Richard W. Woodman and William A. Pasmore (ed.). Research in Organizational Change and Development. An Annual Series Featuring Advances in Theory, Methodology, and Research. 5. Greenwich: JAI Press Inc.

Rosenbaum, S. (1999): What Makes Strategic Usability Fail? Lessons Learned from the Field. Proceedings of CHI '99. Pittsburgh, USA.

Schein, E. (1985): Organizational culture and leadership. $2^{\text {nd }}$ edition. San Francisco: JosseyBass.

Schein, E. (1996): Culture: The Missing Concept in Organization Studies. Administrative Science Quarterly. 41.

Schultz, M. (1994): On Studying Organizational Cultures. Diagnosis and Understanding. Walter de Gruyter: Berlin.

Schultz, M. \& Hatch, M.J. (1996): Living with Multiple Paradigms: the Case of Paradigm Interplay in Organizational Culture Studies. Academy of Management Review. 21(2).

Smircich, L. (1983): Concepts of Culture and Organizational Analysis. Administrative Science Quarterly. 28.

Tata, J. \& Prasad, S. (1998): Cultural and structural constraints on total quality management implementation. Total Quality Management. 9(8).

Zammuto, R.F. \& Krakower, J.Y. (1991): Quantitative and Qualitative Studies of Organizational Culture. In Richard W. Woodman and William A. Pasmore (ed.). Research in Organizational Change and Development. An Annual Series Featuring Advances in Theory, Methodology, and Research. 5. Greenwich: JAI Press Inc. 